\title{
THE FORMATION AS THE BASIS FOR GEOLOGIC MAPPING
}

In a recent number of this Journal Mr. Bailey Willis, in a paper on "Individuals of Stratigraphic Classification," has restated and rediscussed the problem which must be solved before cartographic work of any magnitude can be planned. This problem involves a careful consideration of the relative weights to be assigned, in any system of classification to be used on geologic maps, to faunal, lithologic, and chronologic (successional) characters. Mr. Willis discusses the question in its various aspects, and his final decision is that the lithologic unit (formation) is best adapted to the requirements of the cartographer.

While agreeing, in the main, with the conclusions reached by Mr. Willis, it seems desirable to call attention to certain arguments, not specifically mentioned by him, which may be adduced in support of those conclusions ; and, further, to examine the results of the application of the proposed system of classification to some particular cases of interest.

Before commencing the discussion of this question I wish to acknowledge my indebtedness to Dr. F. J. H. Merrill, director of the New York State Museum, who has greatly aided me, with both criticism and advice, during the preparation of this paper.

THE NECESSITY FOR UNIFORMITY

Though the formation, defined primarily by lithologic characters, was officially adopted in 1889 as the cartographic unit of the United States Geological Survey, in practice it has not entirely superseded other units of classification. Great variety exists in the practice of the various state geological surveys, as is indicated by their official maps; and greater variety, as might indeed be expected, in unofficial maps accompanying papers on 
areal geology, even though the authors be connected with surveys whose official practice is uniform.

In considering the representation on a map of the geological features of a small, isolated area, the question of the taxonomic unit to be employed is usually of minor importance; though even in this case, as shown later, there would seem to be good reasons for the adoption of the lithologic individual as this unit. The interest attaching to this question increases directly with the size of the area to be mapped; and the problem becomes of paramount importance when the independent work of several geologists is to be combined, as in the compilation of a geologic map of an entire state or other large area.

In view of these facts, and of the slow but steady spread of the geologic-folio work carried on by the United States Geological Survey, it would seem necessary that the various local surveys should adopt the same general system of classification for map work. In the present state of our knowledge, detailed chronologic classification, the unit for which would be the epoch $^{x}$ of earth-history, is impossible ; and the problem of unification is therefore resolved into the choice between two alternative systems, based respectively upon biologic and lithologic characters. In the opinion of the writer a geologic survey, whether state or national, can best accomplish the work for which it is intended by adopting as its cartographic and taxonomic unit the formation, defined as a lithologic individual.

THE RELATIVE SCIENTIFIC VALUES OF BIOLOGIC AND LITHOLOGIC UNITS

For the purposes of the present discussion it is necessary to point out that our knowledge of the two histories (i.e., of sedimentation and of life), so far as that knowledge can be expressed on maps, is decidedly different in grade. The present phase of earth-history may be examined for a determination of the truth of this statement. We can map without difficulty the topographic features of the earth; and the possible accuracy and

'The word epoch is here used in an entirely general sense. 
precision of such mapping is limited only by the consideration of expense. Moreover, we are able in most cases to discuss topographic features in terms of causality.

With regard to the present biologic condition of the earth our knowledge is much less definite. Mapping the distribution of existing faunas or floras is not practicable in the present state of our knowledge of biotic ${ }^{x}$ distribution, except in a very general way; anything like a detailed map is impossible. This condition is due partly to the expense of collecting sufficient data on the range of the different species of plants and animals. Most of the difficulty, however, arises from the fact that the principles underlying and regulating animal and plant distribution are still far from being well understood, though of late years great advances have been made in that direction.

If our knowledge is thus imperfect with regard to the existing biota, ${ }^{1}$ our knowledge of the facts and causes of its distribution during past ages is still less definite. It is noteworthy that two of the most successful attempts ${ }^{2}$ to account for biotic distribution and evolution in periods antedating the present have been the work of geologists specializing in physiographic work, a branch which necessitates lithologic rather than biologic discriminations.

Obviously, the paleontologic record must always be more defective than the lithologic; for fossils are not always found where rocks are exposed. In addition to gaps occurring because of local lack of fossils, two periods are particularly incapable of being treated on a biologic basis; one immensely long period at the commencement of geologic history, and one short but highly important periud immediately preceding the beginning of written history.

With regard to the relative values of the biologic and lithologic units as measures of absolute time, the case is somewhat

${ }^{\mathrm{r}}$ Biota $=$ the sum of the fauna and flora of a region. Cf.Stejneger, American Naturalist, February I90 I, p. 89 .

2 T. C. Chamberlin, "Systematic Source of Evolution of Provincial Faunas," Journ. Geul., VI, pp. 597-608, I898. J. B. Woodwor'Th, "Relation between Baseleveling and Organic Evolution," American Geologist, XIV, pp. 209-235, I894. 
in favor of the latter unit; for the relation existing between time taken in deposition and thickness of formation is much more traceable than that between extent of variation and time taken in evolution.

In considering the adoption of a basis for geologic mapping the biologic unit has, therefore, no antecedent claim to special consideration on scientific grounds; and its value can be compared directly with that of the lithologic unit in regard to their relative practicability and utility.

THE RELATIVE PRACTICABILITY OF THE TWO SYSTEMS

A lithologic unit can usually be so described and defined as to be readily identified by any future worker in the same or an adjoining area through which the formation extends.

It should also be noted that all geologists substantially agree upon the use of the terms in which lithologic individuals are defined, and will consequently agree closely in their valuation of any series. "Limestone," "sandstone," "slate," "conglomerate," all have fairly definite meanings, and it is improbable that terms such as these are used in very different senses by different geologists. The biologic unit, on the other hand, is rarely capable of being so described or defined as to be acceptable to all paleontologists. The difference is that the lithologic individual is a fact; the biotic individual, as commonly described, is a fact plus an interpretation; and while there may be substantial agreement as to the facts in any given case, it is but rarely that the interpretations will coincide.

The Hudson formation in the vicinity of Albany, N. Y., presents an excellent example of some of the practical difficulties encountered in attempting to represent faunal distinctions on a map; and a brief sketch of the conditions may be of interest in the present connection.

The "Hudson River group" of the earlier classificationsthe "Hudson formation" of the present system of nomenclature - comprises in the central portion of the Hudson River valley, where it is best developed and exhibited, a thick and extensive 
series of shales, with interbedded sandstones and occasional thin beds or lenses of limestone. This series is well shown along the banks of the Hudson River, extending almost uninterruptedly from Fort Edward to Cornwall. Faunal differences justify the paleontological division of the "group" into four stages, of which the two lower carry a fauna which would correlate them with the Trenton (using that term in its paleontological significance), while the other two represent respectively the Utica and Lorraine beds of the Mohawk valley. This division into stages, however, is and must be largely theoretical, for it cannot well be carried out in practice on a map. Fossils, especially of species which can be regarded as of taxonomic importance, are neither profusely nor regularly distributed throughout the beds in question. Outcrops carrying characteristic fossils are too few and far between to warrant mapping the area, on a paleontological basis, on any large scale. The lithologic differences which occur in the group have no stratigraphic or cartographic value, being too slight and variable to admit of separate representation on a map.

Modern geologic mapping, especially if the base of the map is to be a topographic atlas sheet, in order to make adequate returns for the expense involved, must be accurate within the limit fixed by the scale of the map.

The production of a geologic map is necessarily accomplished by the exercise of two functions, observation and inference. Observation involves the location of outcrops and lithologic boundaries with reference to fixed points in the control of the map, and is therefore purely a matter of engineering. The exercise of the function of inference is necessary in order to indicate the positions of boundaries concealed by superficial material. Inferences in relation to such matters are dependent for their accuracy on the training and judgment of the geologist; his appreciation of the relations existing between structure and topography, and his knowledge of the geometric effects of dip, pitch, etc., in determining the position, both horizontal and vertical, of a concealed boundary line. 
Other things being equal, the determination of the altitude and geographic position of a given point is dependent upon the engineering skill of the observer; and the cartographic unit to be employed does not seriously affect this phase of the work of mapping. With regard to inference, however, this is not the case. No necessary relation exists between a biologic unit and the topography or structure of the area in which it occurs. On the other hand, topography, structure, and the lithologic unit are in general closely related. Recognition of these relations makes it possible to draw inferences concerning the position of the concealed boundary of a lithologic unit from the geologic structure and topography of the area discussed.

\section{THE RELATIVE UTILITY OF LITHOLOGIC AND BIOLOGIC MAPS}

A lithologic unit is normally also an economic unit, whereas there is no necessary relation between the biologic unit and the economic importance, or lack of importance, of the rocks containing a given biota. Though this argument may be regarded by some as of less weight than one based on purely scientific grounds, it is nevertheless valid, as applied to the question under discussion. It should not be forgotten that no geologic survey has ever been instituted, save for economic reasons; that the chief argument that can be used to obtain state support for such surveys is the direct economic return to the public; and that simple justice demands, in return for this support, that the geologic results obtained be placed in such a form as to be of the greatest possible use to that public.

The lithologic unit is also generally related to geographic forms in a very definite manner, as well as to geologic structure. The effects of these relations upon the actual work of mapping have been discussed. Here it is only necessary to point out that both topography and structure are often of economic importance. A map based on a unit which bears some definite relation to them is, therefore, of greater value from an economic standpoint than if the unit be one not so related. 
THE DIFFICULTIES IN MAPPING ON THE LITHOLOGIC BASIS

Difficulties will certainly be encountered in mapping any large area on a lithologic basis, but these difficulties will arise rather from differences in the interpretation of the rules for the nomenclature of the units than from any defects in the system itself. Certain cases of interest in this connection are discussed below :

Case 1.-The case is that cited first by Mr. Willis (p. 563). A shale passes along the strike into a limestone which retains identical stratigraphic associations. "Being exactly continuous stratigraphic units, they should retain the same geographic name on grounds of convenience and simplicity." Considered as a stratigraphic unit, the two would be discussed as the " $X$ " formation. In order to preserve all the advantages of the lithologic system of classification, however, the limestone phase should be differentiated, in both discussion and mapping, from the shale phase; their respective names being then the " $\mathrm{X}$ " limestone and the "X" shale. The term "phase" seems to serve a useful purpose in this connection, and the present writer, therefore, proposes it for use in marking variations of sedimentation or of metamorphism within the stratigraphic unit. When used later in this paper, it will be with this restricted and definite meaning.

This case is illustrated excellently in New York state and western New England, in this example the phases representing variations in metamorphism. The Hudson shales of the central part of New York state are progressively metamorphosed to the eastward, becoming first slates and then mica-schists. The schistose phase has been called, in Massachusetts, the "Berkshire schist;" in southeastern New York, by Merrill, the "Manhattan schist," while Dale has described the intermediate phases as "Hudson slates." Throughout the entire area, though differing thus in character because of variations in metamorphic action, the rocks are essentially continuous stratigraphically; and recognition of this fact has led to the recent proposition to eliminate the names Berkshire and Manhattan, and denote the 
various phases of the Hudson formation by the term "Hudson shale," "Hudson slate," "Hudson schist." This system of nomenclature, while recognizing the essential stratigrapic equivalence and continuity of the various phases, allows these phases to be discriminated from each other on lithologic grounds. On maps this discrimination can best be shown by the use of some of the various overprints used to denote metamorphism.

Case 2.-The second case noted by Mrs. Willis is that of a "shale grading into a limestone with prolonged overlap, so that the two rocks must be discriminated in one area. Not only are they lithologically different but they have different stratigraphic associations, and they should receive distinct" formational names. As noted under the preceding case, this is the condition which usually obtains where there is a horizontal gradation in character of sedimentation. The writer believes that $\mathrm{Mr}$. Willis has here suggested the proper treatment of the question, but wishes to point out an actual case of some areal importance in which this ruling has not been followed.

The example occurs in the northwestern part of Massachusetts. To the west of Hoosac Mountain, the Cambrian quartzite is overlaid by Stockbridge limestone and this in turn by Hudson (Berkshire) schist; on and east of the mountain the limestone does not appear. It has been generally assumed that the schist of the mountain represented both the Berkshire schist and the Stockbridge limestone, and the name "Hoosac schist" has been applied to it in several publications.

What the writer wishes to point out is that, under the proposed rules, the name at present used for one of those formations would seem to be untenable. For, if the eastern (Hoosac) schist represents both the Berkshire schist and Stockbridge limestone, the case becomes the same as 2 , and in that case all the schist should be called Berkshire and all the limestone Stockbridge. If the transition be considered sudden, then it exhibits a slight modification of case 3 , and still all the schist is Berkshire schist and all the limestone Stockbridge limestone. If the relations at Hoosac Mountain be referable to overlap, 
then it is obvious that the Hoosac schist is simply an equivalent of the Berkshire schist, while none of the Stockbridge limestone is represented by any of the schist east of the mountain. On any hypothesis, therefore, the formation name "Hoosac schist" is apparently untenable.

Case 3.- The third example cited by Mr. Willis is that of a shale which varies horizontally in such a manner as to become differentiated into several superposed members, one of which is a similar shale, the others limestone or sandstone. His decision is that in such a case all the shale can be given the same formation name, while the new members (limestone, sandstone, etc.), are to be given distinctive names; but that, in case it be desirable to refer to the group as a whole in some area where it is thus differentiated into several members, the geographic name applied to the shale alone cannot be applied to the entire group.

The last three cases cited by Mr. Willis present instances of subordinate parts or local developments (of the lithologic unit) which, though too small for mapping, are of interest in discussion. To such sections of the unit the terms "member" or "lens" may be applied. This method of treatment and terminology, if followed strictly and uniformly, would seem to be entirely satisfactory.

SUMMARY.

It will be seen that the essential character of the proposed unit is that it is uniform, or uniformly variable, in lithologic character. Both its upper and lower limits and its lateral boundaries will therefore by marked by lithologic differences. So long as the formation is geographically continuous, no other criterion is necessary or even admissible.

In the case of discontinuities in outcrop, caused by the presence of bodies of water, or of intervening areas of other rocks or superficial deposits, the question will arise as to the treatment in mapping of two distinct bodies of rock, identical lithologically. In this case the aid of stratigraphic association or contained fossils may be invoked.

In regard to sharpness of definition, ease and accuracy of 
mapping, and utility of the resulting maps, the lithologic unit would seem to leave little to be desired. Difficulties arising from diverse interpretations of the rules for its discrimination can be overcome with little trouble. A more serious diffculty, however, is to be encountered in regard to the question of the geographic names to be given the units. It is not sufficient to say that the rules of priority will determine the name to be used, even if those rules be re-formulated with special regard to this particular question. The difficulty to which the writer alludes can almost be said to be inherent in the definition of the unit and to be avoidable only by giving a very free interpretation of that definition. It arises when two or more geologists, who commenced work in more or less widely separated areas, have carried areal mapping to a junction. Identical formations will then bear different names on adjoining folios. In regions whose geology is fairly well known, identity of nomenclature can generally be arranged in advance with safety. In less well-known regions, however, the possibility that the same formation may require treatment under different names in adjoining folios will have to be accepted as a necessary evil, largely outweighed by the positive advantages of adopting the lithologic unit as the basis for mapping.

New York State Museum,

Edwin C. Eckel.

Albany, N. Y. 